\title{
Incidentally found cystic lymphangioma of the adrenal gland in an elderly male cadaver
}

\author{
Hee Cheol Kim ${ }^{1}$, Yunji Kang ${ }^{1}$, Young Hee Maeng ${ }^{2}$, Jinu Kim ${ }^{3}$, Sang-Pil Yoon ${ }^{3,4}$ \\ ${ }^{1}$ Medical Course, Jeju National University School of Medicine, Jeju, Korea \\ ${ }^{2}$ Department of Pathology, Jeju National University School of Medicine, Jeju, Korea \\ ${ }^{3}$ Department of Anatomy, Jeju National University School of Medicine, Jeju, Korea \\ ${ }^{4}$ Institute for Medical Science, Jeju National University, Jeju, Korea
}

Received: May 31, 2019

Revised: July 7, 2019

Accepted: July 11, 2019

Corresponding author:

Sang-Pil Yoon

Department of Anatomy, Jeju

National University School of

Medicine, 102, Jejudaehak-ro, Jeju

63243 , Korea

Tel: +82-64-754-3823

Fax: +82-64-725-2593

E-mail: spyoon@jejunu.ac.kr
Adrenal cystic lymphangiomas are extremely rare entities that are often identified incidentally, with less than 60 cases reported to date. We found a protruding ovoid mass consisting of a multiloculated cystic lesion within right adrenal gland in the cadaver of a 75-year-old Korean man. The epithelial cells lining the adrenal cyst were diffusely positive for cluster of differentiation 31 and podoplanin, and negative for pan-cytokeratin. The histopathological diagnosis confirmed a cystic lymphangioma arising from the adrenal gland. Post-mortem findings of the present case are discussed based on the clinicopathological features of adrenal cystic lymphangiomas.

Keywords: Adrenal cyst; Cadaver; Lymphangioma; Male

\section{Introduction}

Benign adrenal vascular pathologies, including tumors, cysts, and pseudocysts, are relatively rare entities that are mostly right-sided and predominantly observed in females [1]. These lesions may occur concomitantly with other adrenal tumors associated with hormone secretion. Cysts of the adrenal glands are rare and often detected incidentally during radiological examinations or at autopsy. Their reported incidence ranges $0.06-0.18 \%$ [2-4].

Adrenal cysts are classified into the following four main groups: endothelial cysts (45\%), pseudocyst (39\%), epithelial cysts (9\%), and parasitic cysts (7\%) [5]. Endothelial cysts include hemangio$\mathrm{ma}$ and lymphangioma [6]. Adrenal cystic lymphangiomas do not exhibit pathognomonic clinical or radiological presentation. Certain features of these entities raise the suspicion of malignancy, including a heterogeneous appearance in imaging analyses, the presence of necrosis in the center of the mass accompanied by calcification, and the size of the adrenal mass [7].

We present a case of a cystic lesion on the right adrenal gland in an elderly man and discuss its common and distinct features.

\section{Case}

We found multiloculated cysts on the right adrenal gland in the cadaver of a 75-year-old Korean man, whose cause of death was pneumonia, during routine educational dissection.

An ovoid cystic mass protruded from the outer surface of the adrenal gland (Fig. 1A). Dissection revealed a multilocular cystic lesion measuring $3.3 \times 3.0 \mathrm{~cm}$ (longest and transverse diameters in external dimension, respectively) within the adrenal gland. The cystic walls were thin, and the cavities contained a pale to tan-colored gelatinous material (Fig. 1B). 

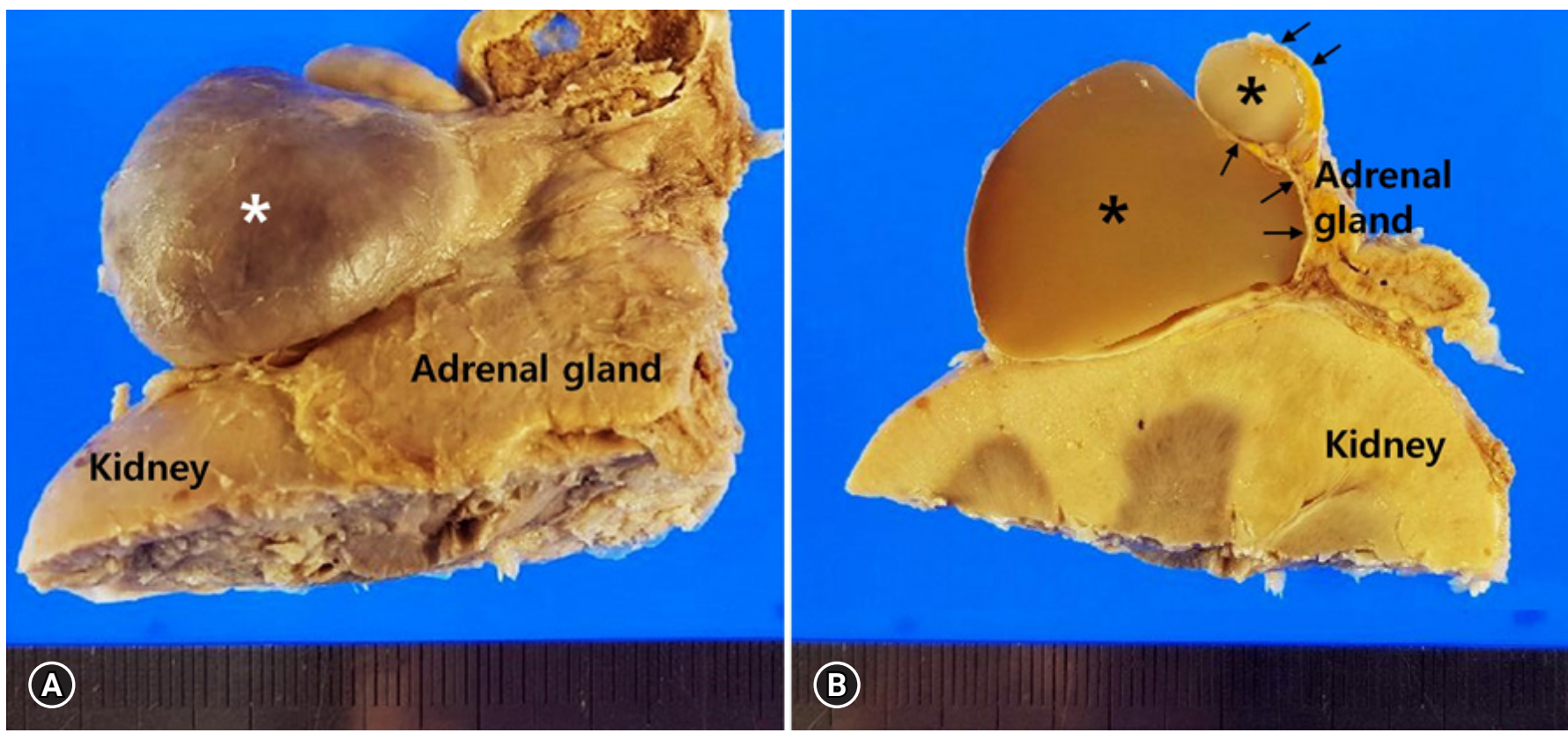

Fig. 1. Gross findings of the right-sided adrenal cystic mass. (A) The protruding mass (asterisk) shows smooth outer surface. (B) The multilocular cystic structures (asterisks) are surrounded by flattened adrenal parenchyma (arrows) on the section surface.

Microscopy analysis revealed that the cystic structures were surrounded by flattened adrenal parenchyma (Figs. 2A, 2B) and the inner surfaces were lined by a single layer of flattened cells with bland nuclei (Fig. 2C). The lining cells were diffusely positive for cluster of differentiation 31 (CD31) (Fig. 2D) and podoplanin (D2-40) (Fig. 2E), and negative for pan-cytokeratin (Fig. 2F). The pathological diagnosis confirmed a cystic lymphangioma arising from the adrenal gland.

\section{Discussion}

Lymphangiomas, benign malformations of lymphatic vessels, are most frequently noted in children aged less than 2 years $[8,9]$. Although the exact cause has not been established yet, these entities are generally regarded as congenital malformations in which obstruction or agenesis of lymphatic tissue results in lymphangiectasia due to a lack of normal communication within the lymphatic system $[8,10]$. The majority of lymphangiomas are detected in the neck, axillary region and mediastinum (95\%), and the remaining $5 \%$ are found in the abdominal cavity [8,11]. Adrenal lymphangiomas account for less than $1 \%$ of all abdominal lymphangiomas [12]. To date, less than 60 adrenal lymphangioma cases have been described [13], with only 7 cases reported in Korean [14].

While lymphangiomas are typically detected in childhood and are rare in adults, adrenal lymphangiomas are predominantly noted in women in aged approximately 40 years, mostly right-sided, and unilateral (mean size $8.9 \mathrm{~cm}$; range $2.0-35.0 \mathrm{~cm}$ ). Histologically, all adrenal lymphangiomas show a typical multicystic lesion composed of irregular dilated spaces that are lined by flattened bland simple endothelial cells [12] and have potential malignancy incidence of about $4.1 \%[10,15]$. Adrenal cystic lymphangiomas are usually asymptomatic because of their size and location [8]. The most common complaint is pain, which is localized in back, the right upper quadrant of abdomen, or is generalized as abdominal pain [10]. Transabdominal adrenalectomy is the treatment of choice. Recent recommendations entail the aspiration of material from the adrenal cysts instead of their surgical excision both for diagnosis and management, in cases where malignancy is not suspected or the lesion is non-functional and asymptomatic $[6,8,10,12,16]$.

In conclusion, small asymptomatic adrenal cystic lymphangiomas without malignant transformation were incidentally detected in an elderly Korean male cadaver and the diagnosis was confirmed by histopathological staining for CD31 and D2-40. Unlike other adrenal cystic lymphangiomas, the adrenal lymphangioma in the present case was detected in an elderly male cadaver due to their size during postmortem investigation. Therefore, careful inspection of the adrenal cysts by clinicians and anatomists is warranted, despite the patient's age and sex. 


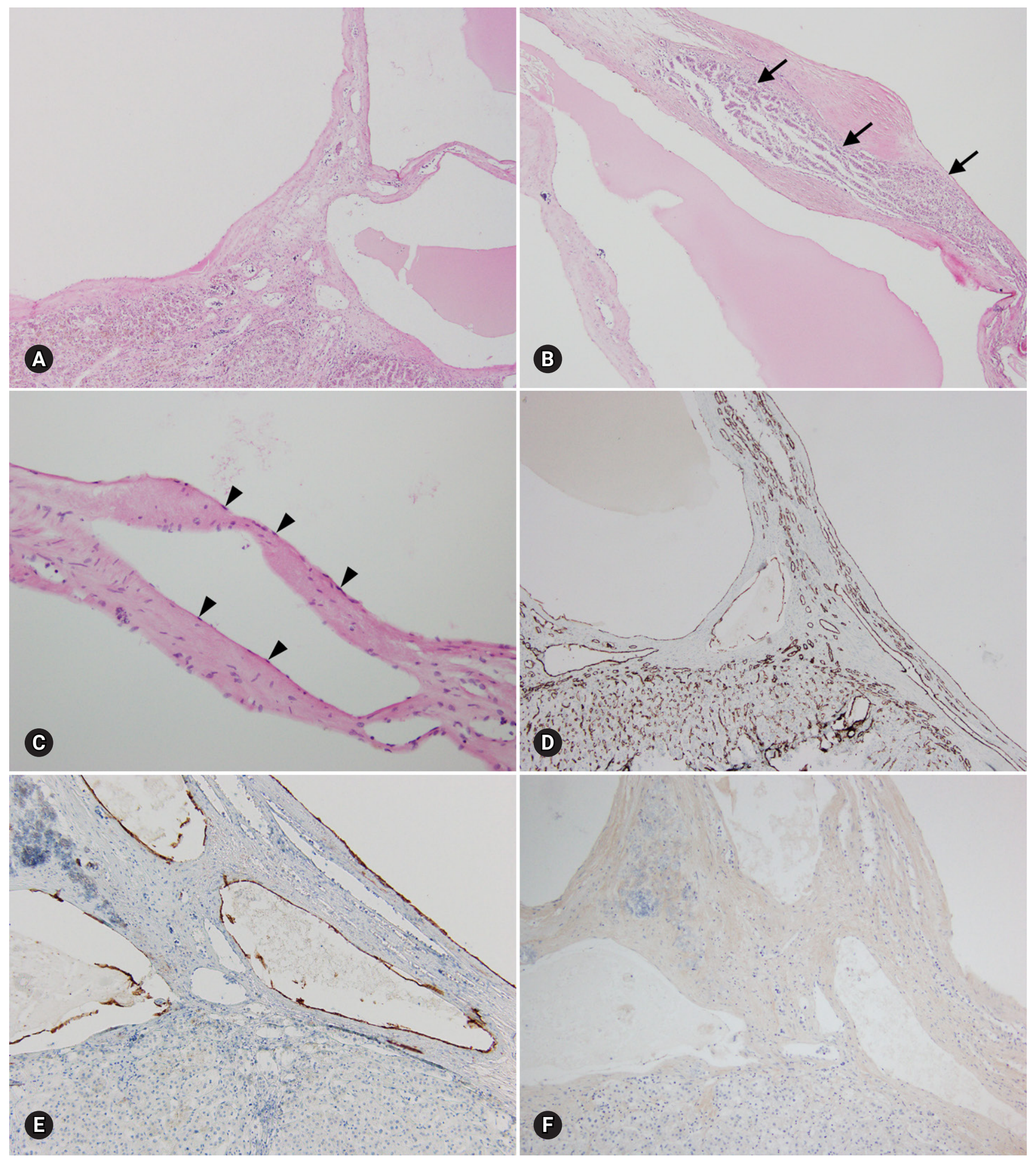

Fig. 2. Microscopic findings of the right-sided adrenal cystic lesion. (A) Multilocular cystic spaces are present. (B) Entrapped adrenal parenchyma (arrows) is present. (C) The cystic wall is lined by a single layer of flattened endothelial cells (arrowheads) (hematoxylin and eosin stain, $\times 40[A$ and B] and $\times 200[C]$ ). The lining endothelial cells are positive for cluster of differentiation 31 (D) and podoplanin (E), and negative for pan-cytokeratin (F) (immunohistochemical stain, $\times 40[D]$ and $\times 100[E$ and F]). 


\section{Acknowledgements}

This work was supported by the 2019 education, research and student guidance grant funded by Jeju National University.

\section{Conflicts of interest}

No potential conflicts of interest relevant to this article was reported.

\section{ORCID}

Hee Cheol Kim, https://orcid.org/0000-0002-1820-1543

Yunji Kang, https://orcid.org/0000-0001-9082-4107

Young Hee Maeng, https://orcid.org/0000-0003-3168-6482

Jinu Kim, https://orcid.org/0000-0002-1313-4791

Sang-Pil Yoon, https://orcid.org/0000-0003-1350-3582

\section{References}

1. Zheng W, Fung KM, Cheng L, Osunkoya AO. Benign vascular tumors, cysts, and pseudocysts of the adrenal gland: a contemporary multi-institutional clinicopathological analysis of 55 cases. Hum Pathol 2018;82:95-102.

2. Pollack HM. Miscellaneous conditions of the adrenals and adrenal pseudotumors. Clin Urogr 1990;3:2403-5.

3. Rozenblit A, Morehouse HT, Amis ES Jr. Cystic adrenal lesions: CT features. Radiology 1996;201:541-8.

4. Tagge DU, Baron PL. Giant adrenal cyst: management and review of the literature. Am Surg 1997;63:744-6.

5. Foster DG. Adrenal cysts. Review of literature and report of case.
Arch Surg 1966;92:131-43.

6. Longo JM, Jafri SZ, Bis KB. Adrenal lymphangioma: a case report. Clin Imaging 2000;24:104-6.

7. Rowe SP, Bishop JA, Prescott JD, Salvatori R, Fishman EK. CT appearance of adrenal cystic lymphangioma: radiologic-pathologic correlation. AJR Am J Roentgenol 2016;206:81-5.

8. Ates LE, Kapran Y, Erbil Y, Barbaros U, Dizdaroglu F. Cystic lymphangioma of the right adrenal gland. Pathol Oncol Res 2005;11:242-4.

9. Kafadar MT, Özyuvalı E, Miryaguboğlu AM, Çaviş T, İnan A. Incidental giant adrenal lymphangioma presenting as nonfunctional cystic mass. Turk J Surg 2018;1-3. [Epub ahead of print].

10. Michalopoulos N, Laskou S, Karayannopoulou G, Pavlidis L, Kanellos I. Adrenal gland lymphangiomas. Indian J Surg 2015;77(Suppl 3):1334-42.

11. Poncelet V. Retroperitoneal cystic lymphangioma. J Belge Radiol 1998;81:245.

12. Ellis CL, Banerjee P, Carney E, Sharma R, Netto GJ. Adrenal lymphangioma: clinicopathologic and immunohistochemical characteristics of a rare lesion. Hum Pathol 2011;42:1013-8.

13. Bibi M, Sellami A, Taktak T, Chelly B, Ghorbel Z, Zouari H, et al. Giant cystic lymphangioma of adrenal gland: a case report and review of the literature. Urol Case Rep 2018;22:6-7.

14. Kim KH, Lee JI, Bae JM. Significant growth of adrenal lymphangioma: a case report and review of the literature. Int J Surg Case Rep 2015; 17:48-50.

15. Tanuma Y, Kimura M, Sakai S. Adrenal cyst: a review of the Japanese literature and report of a case. Int J Urol 2001;8:500-3.

16. Satou T, Uesugi T, Nakai Y, Hayashi Y, Imano M, Hashimoto S. Case of adrenal lymphangioma with atypical lymphocytes in aspirate cytology. Diagn Cytopathol 2003;29:87-90. 